\title{
Development of degradable pre-formed particle gel (DPPG) as temporary plugging agent for petroleum drilling and production
}

\author{
Dao-Yi Zhu ${ }^{1} \cdot$ Xing-Yu Fang $^{1} \cdot$ Ren-Xian Sun ${ }^{1} \cdot$ Zeng-Hao Xu $^{1} \cdot$ Yang Liu $^{1} \cdot$ Ji-Yang Liu $^{1}$
}

Received: 19 August 2020 / Accepted: 9 November 2020 / Published online: 28 November 2020

(c) The Author(s) 2020

\begin{abstract}
Temporary plugging agent (TPA) is widely used in many fields of petroleum reservoir drilling and production, such as temporary plugging while drilling and petroleum well stimulation by diverting in acidizing or fracturing operations. The commonly used TPA mainly includes hard particles, fibers, gels, and composite systems. However, current particles have many limitations in applications, such as insufficient plugging strength and slow degradation rate. In this paper, a degradable pre-formed particle gel (DPPG) was developed. Experimental results show that the DPPG has an excellent static swelling effect and self-degradation performance. With a decrease in the concentration of total monomers or cross-linker, the swelling volume of the synthesized DPPG gradually increases. However, the entire self-degradation time gradually decreases. The increase in 2-acrylamide-2-methylpropanesulfonic acid (AMPS) in the DPPG composition can significantly increase its swelling ratio and shorten the self-degradation time. Moreover, DPPG has excellent high-temperature resistance $\left(150{ }^{\circ} \mathrm{C}\right)$ and high-salinity resistance $(200,000 \mathrm{mg} / \mathrm{L} \mathrm{NaCl})$. Core displacement results show that the DPPG has a perfect plugging effect in the porous media (the plugging pressure gradient was as high as $21.12 \mathrm{MPa}$ ), and the damage to the formation after degradation is incredibly minor. Therefore, the DPPG can be used as an up-and-coming TPA in oil fields.
\end{abstract}

Keywords Temporary plugging agents $\cdot$ Pre-formed particle gel (PPG) $\cdot$ Degradable PPG $\cdot$ Petroleum drilling $\cdot$ Petroleum production

\section{Introduction}

In recent years, temporary plugging technology has been widely used in various fields of petroleum reservoir drilling and production (Kang et al. 2014; Xiong et al. 2018; Zhang et al. 2019a). The design idea of temporary plugging technology is to use plugging agents (usually chemical agents) to plug the flow channels (i.e., layers with higher permeability) (Li et al. 2019; Liu et al. 2018). However, in the subsequent oil and gas production process, it is hoped that the agents sealing in the layers can be effectively removed or self-recovered (Zhang et al. 2020a). In this way, the oil and gas flow channels can be further increased or expanded, and more crude oil and natural gas can be produced. For

Edited by Yan-Hua Sun

Dao-Yi Zhu

chutaoi@163.com

1 College of Petroleum, China University of Petroleum-Beijing at Karamay, Karamay 834000, Xinjiang, China example, the use of temporary plugging technology during drilling can shield and protect oil and gas reservoirs during drilling. It can avoid damaging the permeability of the reservoir and ensure that oil and gas can flow easily to the wellbore and be produced. Besides, in the process of oil and gas reservoir developement, if the reservoir permeability is low, stimulation technologies such as acidification and fracturing of the formation are required (Zhang et al. 2020a, b). Temporary plugging technology can be used to plug the treated layers so that subsequent treatment agents (e.g., fracturing fluid or acid, etc.) can be diverted into other untreated layers (Xue et al. 2015). In this way, the reservoir conformance can be improved, and thereby increasing oil and gas production (Jia et al. 2020). Take the multi-stage fracturing process as an example, as shown in Fig. 1. If the temporary plugging technology is used in multiple fracturing processes, it can divert the subsequent injection of high-energy fracturing fluids to form a more effective and complex fracture network (Wang et al. 2020; Yuan et al. 2020). Therefore, the flow conductivity and oil drainage area can be improved to increase the single well production. 


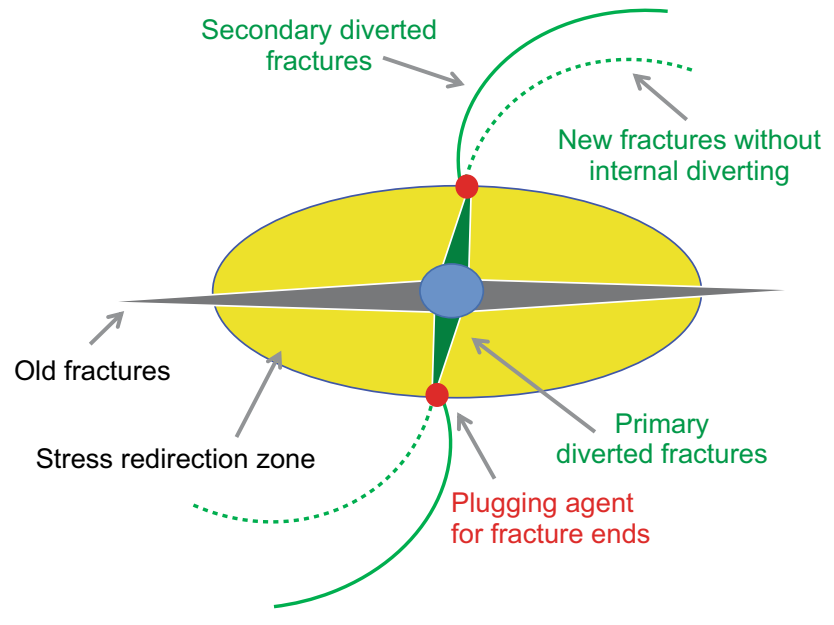

Fig. 1 Schematic diagram of multiple fracturing by diverting process (Du et al. 2013)

Temporary plugging agent (TPA) differs from conventional plugging materials in that it can dissolve in the formation water or fracturing fluids, or it can be self-degraded after the diverting operation is completed. Therefore, it can cause little damage to the formation (Zhao et al. 2020). After years of development, there are many types of temporary plugging agents, mainly divided into the following four types. They are granular TPA (Liu et al. 2020; Shi et al. 2020), fiber-type TPA (Zhang et al. 2019b, c), gel-type TPA (Nasiri et al. 2018; Zhao et al. 2016), and compound TPA (Li et al. 2020; Liu et al. 2020).

Non-deformable granular TPA includes water-soluble inorganic salt particles (e.g., calcium carbonate), oil-soluble particles (e.g., wax balls and resin), and temperaturesensitive degradable particles (e.g., polylactic acid). They mainly rely on the mechanism of particle bridging effect to accumulate in the fractures or pore throats to form temporary plugging layers (Allison et al. 2011). However, the granular TPA is generally made of inorganic salt particles with high compressive strength, which has a low crushing rate and high compressive strength. Therefore, the inability to deform causes this type of TPA to have limited adaptability and requires manual selection, which increases the difficulty of oilfield operations. Gel-type TPA mainly refers to water-soluble polymer gels. The gel-type TPA can generate a glue liquid named gelant on the ground. After the gelant is injected into the reservoir, it will undergo a cross-linking reaction to form a temporary plugging layer and seal the fractures. Then, the chase gel breaker is injected to react with the polymer gel, and it will de finally degraded it into a lowviscosity liquid, reducing damage to the reservoir (Wang et al. 2019a). The fiber-type TPA realizes the plugging effect mainly through the three processes of capturing, bridging, and compacting ( $\mathrm{Li}$ et al. 2019). After plugging treatments, the fiber-type TPA can be completely dissolved in water or residual acid, which can protect the reservoir from damage.

Conventional non-deformable granular TPA can be subdivided into water-soluble or acid-soluble inorganic salt particles, oil-soluble particles, and temperature-sensitive degradable particles. These particles mainly rely on the particle bridge plugging effect to form temporary plugging layers at fractures or pore throats and follow to meet the plugging requirement that the particle size should be larger than $1 / 3-1 / 2$ of the pore throat size (Cargnel and Luzardo 1999). Huo (2009) used oil-soluble resins with different softening points to synthesize a new type of oil-soluble temporary plugging agent. The temporary plugging efficiency was more than $94 \%$, and the permeability recovery percentage in oil was more than $90 \%$, which can meet most of the fracturing operation requirements. Jiang and $\mathrm{Mu}$ (2006) experimentally investigated the thermal stability, compatibility with crude oil, pressure, dissolution rate, plugging, and backflow properties of wax plugging agents. The performance of the wax balls could meet the requirements of the temporary plugging and repeated fracturing process in the Ansai Oilfield, China, with excellent performance and reasonable cost. Cargnel and Luzardo (1999) found calcium carbonate $\left(\mathrm{CaCO}_{3}\right)$ could be used as a bridging agent and applied in drill-in fluids; it can prevent massive loss circulation to the reservoir formation (Nasiri et al. 2017).

At present, the most commonly used temperature-sensitive degradable particles are made of polylactic acid (PLA) (Lv et al. 2019; Schultz et al. 2020; Surjaatmadja and Todd 2009). PLA is a new type of biodegradable material made from starch extracted from renewable plant resources (such as corn) (Takahashi et al. 2016). It is reported that it can be degraded by microorganisms in nature, and eventually generate carbon dioxide and water without polluting the environment (Reddy and Cortez 2013). The degradation of polylactic acid is divided into two stages. First, it is hydrolyzed into lactic acid monomers. Then, the lactic acid monomers are degraded into carbon dioxide and water under the action of microorganisms. However, it takes about 60 days for polylactic acid to degrade completely. Reddy et al. (2018) conducted a detailed study on the degradation ability of polylactic acid temporary plugging agents. They found that when using polylactic acid as the temporary plugging agents, degradation accelerators need to be added to shorten the degradation time. Commonly used accelerators include ethylenediamines, ethanolamines, polyamines. However, polylactic acid has an insufficient plugging strength, too fast degradation rate, slow degradation rate, and inadequate mechanical property of polybutyrate. Therefore, Xiong et al. (2018) used polyglycolic acid, polylactic acid (PLA), polybutylene butyrate, and other similar prepolymers to synthesize new degradable polyester materials. The degradation temperature of the materials can be adjusted to 
adapt to degradation requirements of different bottom hole temperatures by optimizing the ratio of raw materials.

Although the fiber-type material has excellent flexibility and outstanding leak-proof and plugging performance, its degradation rate is slow, and strength is limited (Zou et al. 2019). It is challenging to penetrate deeply into the fracture or the tip of the fracture. Besides, the cost of degradable fibers is prohibitive (Zhao et al. 2020). In addition, non-deformable TPA (e.g., inorganic particles, hard resins, polylactic acid) has a specific compressive strength. However, due to the large pores between the stacked particles, the plugging strength is limited (Wei 2017). Moreover, the rigid particles are easily crushed under high pressures, and may not be able to maintain a permanent and effective fracture opening. Pre-formed particle gel (PPG) can be changed into deformable particle after absorbing water (Wang et al. 2019b; Zhu et al. 2017a). Because of its easy injection, strong plugging strength, and excellent environmental protection, it is widely used in profile control and water shutoff operations (Bai et al. 2007a, b; Wang and Bai 2018). However, there are few reports on its use as a temporary plugging agent. The main reason is that conventional PPG was crosslinked by $N, N$ '-methylene bisacrylamide (NMBA), which is thermal-stable in low and medium temperature reservoirs (Zhou 2011).

In this study, we synthesized a degradable pre-formed particle gel (DPPG) as a temporary plugging agent (TPA), which introduced a cross-linking structure that can be selfdegraded under reservoir conditions. The bottle test method was first used to investigate the effects of different formulations (e.g., total monomer concentration, cross-linking agent concentration, initiator concentration, and monomer ratio) on swelling volume and degradation performance of DPPG. Then, reservoir adaptability of the optimized temporary plugging agent (e.g., brine salinity and formation temperature) was evaluated. Subsequently, the polymerization and self-degradation mechanism of DPPG were explained based on the static experimental results and the microscopic morphology and structure changes of DPPG. Finally, the core displacement experiment was used to investigate the plugging and degradation performance of DPPG in the porous medium. This research can provide a theoretical and experimental basis for the further oilfield application of the temporary plugging agent.

\section{Experiment materials and methods}

\subsection{Materials}

The main experimental materials are monomers (e.g., acrylamide, AM, 2-acrylamide-2-methylpropanesulfonic acid, AMPS, Shanghai Macklin Co., Ltd), cross-linker
(DT-2, the main functional group is acrylate, Beijing Yuanyang Huanyu Petroleum Technology Co., Ltd.), initiator (potassium persulfate, KPS, 99.5\%, Shanghai Macklin Co., Ltd.), $\mathrm{NaCl}$ (99.5\%, Shanghai Maclean Co., Ltd.), artificial core (Beijing Yuanyang Petroleum Technology Co., Ltd.), etc. The physical parameters of the artificial core are shown in Table 1.

To investigate the temporary plugging effect of the degradable pre-formed particle gel (DPPG) under oilfield conditions, the physical model used in this experiment was designed and fabricated. The main design and fabrication of physical models are main shown in Fig. 2.

\subsection{Preparation of DPPG}

The preparation method of DPPG is the same as that of conventional PPG (Elsharafi and Bai 2016). First, a certain number of water-soluble monomers (such as AM and AMPS) were weighed and dissolved in a certain amount of reverse osmosis (R.O.) water. After a complete dissolution was achieved, a certain amount of cross-linker (DT-2) and initiator (potassium persulfate) were added in sequence. After being fully dissolved again, it was placed in a thermostat water bath at $45^{\circ} \mathrm{C}$ for heating and reacting for three hours. Then they were dried and crushed and finally DPPG samples were obtained, with different particle sizes and various compositions, as shown in Fig. 3. In this study, twenty DPPGs with different total monomers, cross-linker, initiator concentrations, or different monomer ratios were synthesized. Their formulations are shown in Table 2.

\subsection{Evaluation of static experiments (Bottle test method)}

The bottle test method was used to observe the swelling ratio and degradation of the temporary plugging agent (TPA) under different conditions. First, a certain amount of DPPG was put into a transparent and scaled test tube with enough solvent. For example, $0.1 \mathrm{~g}$ of DPPG with the dry particle size of 20-30 mesh was added to $20 \mathrm{~mL}$ of $\mathrm{NaCl}$ aqueous solution. Then it was put in a thermostat water bath (e.g., $65^{\circ} \mathrm{C}$ ). The packed volume of DPPG in the test tube was recorded with time. The correspondence between swelling time and reading interval and oilfield operation process are shown in Table 3.

As shown in Table 3, the packed volume of swollen DPPG was recorded every $10 \mathrm{~min}$ in the first two hours to simulate

Table 1 Physical parameters of the artificial core used in the core flooding experiment

\begin{tabular}{llll}
\hline Length, cm & Diameter, cm & Porosity, $\%$ & Gas permeability, $10^{-3} \mu \mathrm{m}^{2}$ \\
\hline 10.02 & 2.50 & 15.43 & 18.87 \\
\hline
\end{tabular}


Drilling a hole

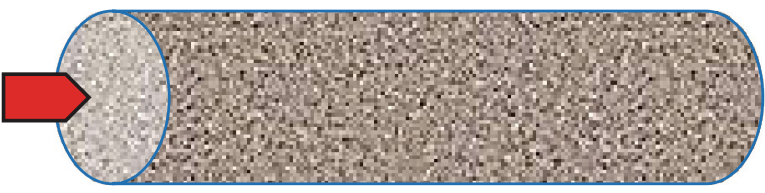

(a) Artificial core before being drilled

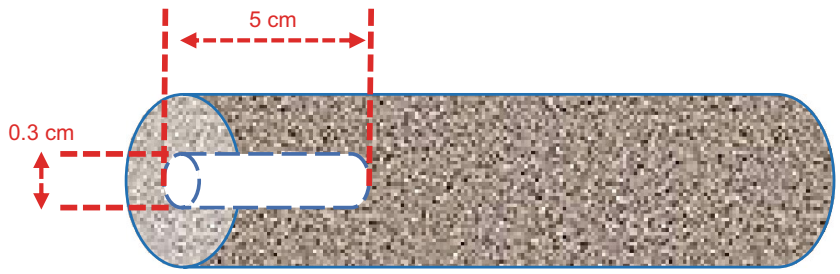

(b) Drilled core

Fig. 2 Fabrication of the physical model

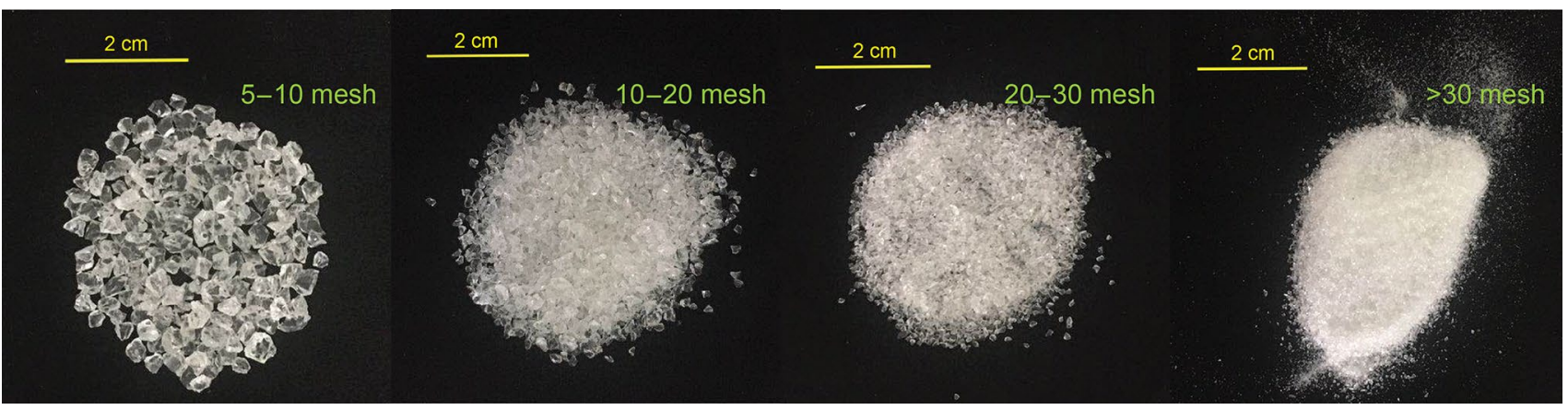

Fig. 3 DPPG C14 with different particle sizes

Table 2 Formulations of DPPG samples with different compositions

\begin{tabular}{|c|c|c|c|c|c|c|}
\hline DPPG No. & AM, wt $\%$ & AMPS, wt $\%$ & $\begin{array}{l}\text { Total monomers, } \\
\text { wt } \%\end{array}$ & $\begin{array}{l}\text { Mass ratio of AM to } \\
\text { AMPS }\end{array}$ & Cross-linker, wt $\%$ & Initiator, wt $\%$ \\
\hline $\mathrm{C} 1$ & 8.4 & 3.6 & 12 & $7: 3$ & 0.12 & 0.8 \\
\hline $\mathrm{C} 2$ & 11.2 & 4.8 & 16 & $7: 3$ & 0.12 & 0.8 \\
\hline $\mathrm{C} 3$ & 14.0 & 6.0 & 20 & $7: 3$ & 0.12 & 0.8 \\
\hline $\mathrm{C} 4$ & 16.8 & 7.2 & 24 & $7: 3$ & 0.12 & 0.8 \\
\hline $\mathrm{C} 5$ & 19.6 & 8.4 & 28 & $7: 3$ & 0.12 & 0.8 \\
\hline C6 & 16.8 & 7.2 & 24 & $7: 3$ & 0.04 & 0.8 \\
\hline $\mathrm{C} 7$ & 16.8 & 7.2 & 24 & $7: 3$ & 0.08 & 0.8 \\
\hline C8 (C4) & 16.8 & 7.2 & 24 & $7: 3$ & 0.12 & 0.8 \\
\hline C9 & 16.8 & 7.2 & 24 & $7: 3$ & 0.16 & 0.8 \\
\hline $\mathrm{C} 10$ & 16.8 & 7.2 & 24 & $7: 3$ & 0.20 & 0.8 \\
\hline C11 & 16.8 & 7.2 & 24 & $7: 3$ & 0.12 & 0.4 \\
\hline $\mathrm{C} 12(\mathrm{C} 4)$ & 16.8 & 7.2 & 24 & $7: 3$ & 0.12 & 0.8 \\
\hline $\mathrm{C} 13$ & 16.8 & 7.2 & 24 & $7: 3$ & 0.12 & 1.2 \\
\hline $\mathrm{C} 14$ & 16.8 & 7.2 & 24 & $7: 3$ & 0.12 & 1.6 \\
\hline C15 & 16.8 & 7.2 & 24 & $7: 3$ & 0.12 & 2.0 \\
\hline C16 & 7.2 & 16.8 & 24 & $3: 7$ & 0.12 & 0.8 \\
\hline C17 & 9.6 & 14.4 & 24 & $4: 6$ & 0.12 & 0.8 \\
\hline C18 & 12.0 & 12.0 & 24 & $5: 5$ & 0.12 & 0.8 \\
\hline C19 & 14.4 & 9.6 & 24 & $6: 4$ & 0.12 & 0.8 \\
\hline C20 (C4) & 16.8 & 7.2 & 24 & $7: 3$ & 0.12 & 0.8 \\
\hline
\end{tabular}


Table 3 Correspondence between swelling time and recording interval and operation process

\begin{tabular}{|c|c|c|}
\hline Time interval & Record procedure & Corresponding oilfield operation process \\
\hline $0-2 \mathrm{~h}$ & Record every 10 min & $\begin{array}{l}\text { Simulate the swelling performance when DPPG is prepared in the mixing tank } \\
\text { on the ground }\end{array}$ \\
\hline $2-5 \mathrm{~h}$ & Record every $30 \mathrm{~min}$ & $\begin{array}{l}\text { Simulate the swelling performance in the wellbore before DPPG is injected into } \\
\text { the formation }\end{array}$ \\
\hline $5 \mathrm{~h}$ & $\begin{array}{l}\text { Take away the solution in the test tube and } \\
\text { record the swollen DPPG volume }\end{array}$ & $\begin{array}{l}\text { Simulate when DPPG is injected into the target horizon, free water will flow } \\
\text { into pores and throats in the formation due to the pressure gradient, only swol- } \\
\text { len DPPGs without free water exist }\end{array}$ \\
\hline After $5 \mathrm{~h}$ & Record every day until degradation is complete & Simulate the self-degradation of DPPG in the target layer \\
\hline
\end{tabular}

the swelling performance when the DPPG is prepared in the mixing tank on the ground. Then, it was investigated every $30 \mathrm{~min}$ from 2 to $5 \mathrm{~h}$ to simulate the swelling performance in the wellbore before the DPPG is injected into the formation. At the time the DPPG was aged in brine for five hours, the solution in the test tube was taken away, and the packed volume was recorded. This process is to simulate the following situation. When the DPPG is injected into the target horizon, free water will flow into the pores and throats in the formation due to the pressure gradient, only the swollen DPPG without free water exists. After that, the swollen DPPG samples without free water were aged in an oven at $65^{\circ} \mathrm{C}$, and the packed volume of the gel was recorded every day. The time when the DPPG samples change from a solid gel to a flowable liquid state without visible particles is defined as the entire degradation time in this study. Each experiment was repeated three times to reduce the experimental error.

\subsection{Infrared spectrum analysis}

A Fourier transform infrared (FT-IR) spectrometer (Nicolet iS20, Thermo Fisher Scientific) was used to measure the infrared spectrum of the sample. Before test, the DPPG particles were dried and ground with $\mathrm{KBr}$ powder. The mixture was compressed in a pellet for FT-IR analysis.

\subsection{Microstructure test}

An optical microscope (Axio Vert.A1, the Carl Zeiss Company) was used to observe the morphological changes of the swollen DPPG during the entire dynamic degradation process. After being aged for different times, the DPPG particles were placed under an optical microscope with a magnification of ten times. The observation process can keep the original appearance of the DPPG that swells by water absorption unchanged. In addition, a scanning electron microscope (SEM, Hitachi S4700, Tokyo, Japan) was used to observe the microscopic changes in the skeleton structure before and after the degradation of DPPG. During the experiment, the DPPG before and after degradation needed to be freeze-vacuum dried, and liquid nitrogen was used as the freezing liquid. After the sample was freeze-dried, conductive glue was employed to stick the dry DPPG sample on the sample stage. Finally, gold was sprayed to enhance its conductivity.

\subsection{Core displacement experiment}

The core displacement experiment was used to evaluate the temporary plugging performance of DPPG in porous media. The experimental device diagram is shown in Fig. 4. The core was placed in the core holder, and the confining pressure was $25 \mathrm{MPa}$. First, brine was injected into the core at a constant flow rate of $0.5 \mathrm{~mL} / \mathrm{min}$ by an ISCO pump until the displacement pressure was stable. Then, the swollen DPPG was injected into the core at a constant flow rate of $1 \mathrm{~mL} / \mathrm{min}$ until the displacement pressure reaches the preset value (i.e., $20 \mathrm{MPa}$ ). After that, brine was injected into the core again at a constant flow rate of $0.5 \mathrm{~mL} / \mathrm{min}$. During the flooding process, the real-time changes of the pressure and the breakthrough pressure gradient during the experiment were recorded. After that, the core holder with the remaining DPPG was aged in the oven at $65^{\circ} \mathrm{C}$. After the remaining DPPG was completely degraded, the core holder was installed in the experimental setup. Please note that the inlet and outlet of the core were swapped to simulate the flow back production process of the petroleum reservoir. Brine was injected again to calculate the reservoir damage of DPPG.

The core permeability can be calculated by the Darcy equation,

$Q=\frac{K A \Delta p}{\mu L}$

where $Q$ is the flow rate through the core under the pressure gradient $\Delta p, \mathrm{~cm}^{3} / \mathrm{s} . A$ is the cross-sectional area of the core, $\mathrm{cm}^{2} . L$ is the length of the core, $\mathrm{cm} . \mu$ is the fluid viscosity, $\mathrm{mPa}$ s. $\Delta p$ is the pressure gradient between the inlet and outlet of the core, $0.1 \mathrm{MPa}$. $K$ is the proportionality coefficient, which is the permeability of the porous medium, $\mu \mathrm{m}^{2}$. 


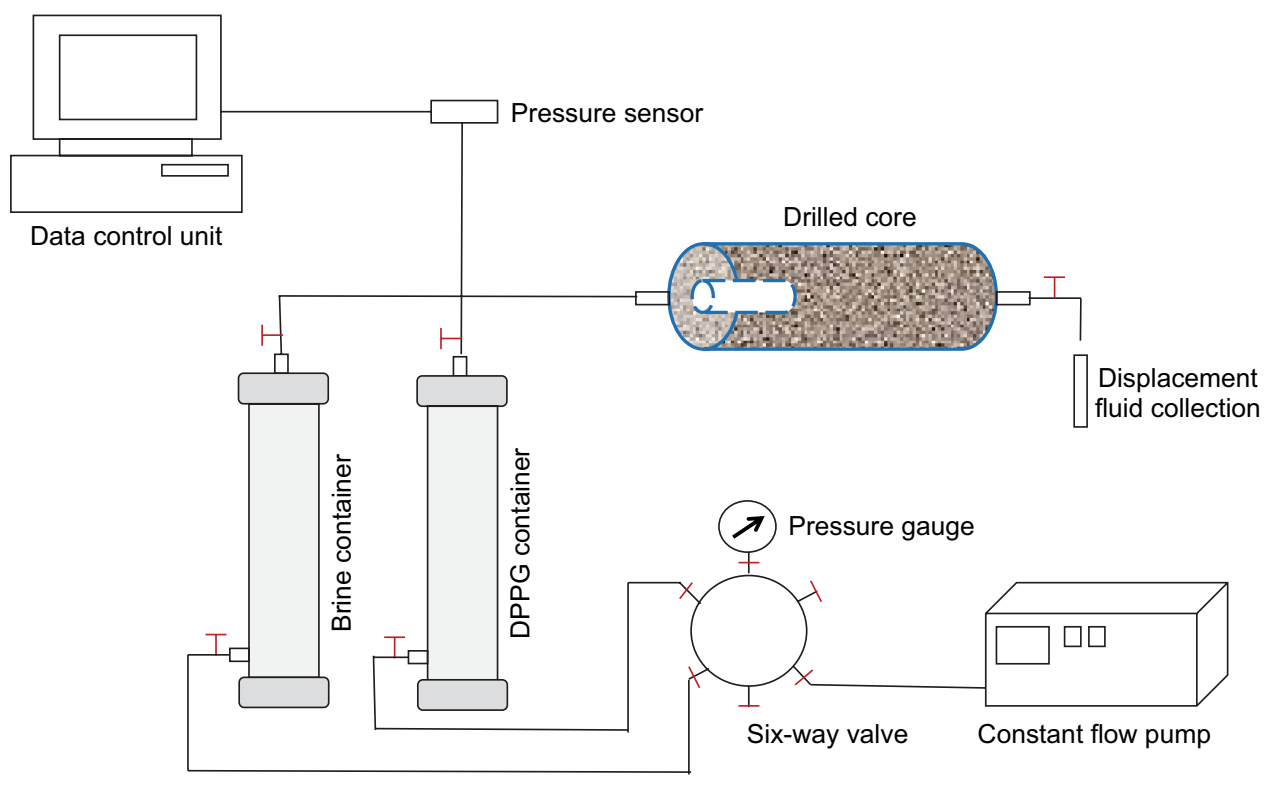

Fig. 4 Schematic diagram of the experimental device for temporary plugging test

\section{Results and discussion}

\subsection{Preparation and characterization of DPPG}

According to the different formulations in Table 2, different types of DPPG samples can be synthesized by free radical polymerization. Monomers such as AM and AMPS are connected to a long chain through free radical polymerization. During this reaction, DT-2, which has a self-degrading function, acts as a cross-linker. It can connect the above polymer chains to form an intricate three-dimensional (3D) network structure.

We can take the DPPG C4 sample as an example. Its infrared spectrum is shown in Fig. 5. The peak at $3500 \mathrm{~cm}^{-1}$ can be attributed to the superposition of the stretching vibration absorption peaks of $-\mathrm{NH}_{2}$. In addition, the peak at $1654.19 \mathrm{~cm}^{-1}$ is the $\mathrm{C}=\mathrm{O}$ stretching vibration in the amide group, which is the characteristic peak of polyacrylamide. The flexural vibration absorption peak at $1449.66 \mathrm{~cm}^{-1}$ attributable to $-\mathrm{CH}_{3}$ is the characteristic peak of AMPS. Moreover, the peak at $1182.85 \mathrm{~cm}^{-1}$ is attributable to the characteristic vibration frequency of C-N. The absorption peak at $1039.70 \mathrm{~cm}^{-1}$ is attributed to the $\mathrm{C}-\mathrm{O}$ bending vibration, which is the characteristic peak of the cross-linker DT-2. Last, the peaks at 802 and $627.41 \mathrm{~cm}^{-1}$ are the out-of-plane bending vibration frequencies of $-\mathrm{NH}$.

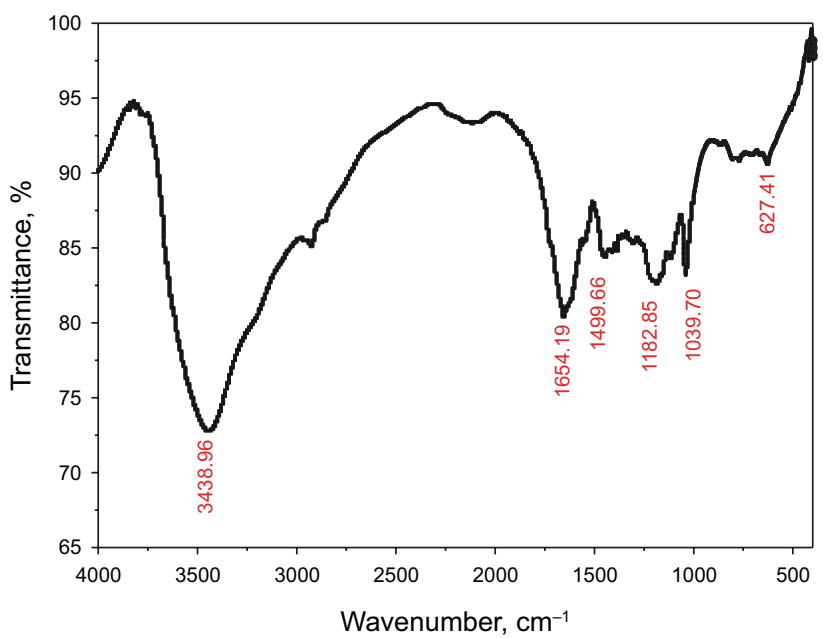

Fig. 5 Infrared spectrum of the DPPG C4 sample

\subsection{Effect of monomer concentrations on the static swelling and degradation performance of DPPG}

To investigate the effect of monomer concentrations on the swelling volume and the degradation time of DPPG, we carried out the static evaluation experiment. The experimental sample was the DPPG $\mathrm{C} 1$ to $\mathrm{C} 5$, the brine used was $1 \% \mathrm{NaCl}$ solution, and the test temperature was $65^{\circ} \mathrm{C}$. The specific compositions of the DPPG $\mathrm{C} 1$ to $\mathrm{C} 5$ are shown in Table 2. Figure 6 gives the swelling and degradation performance of DPPG $\mathrm{C} 1$ to $\mathrm{C} 5$ composed of different monomers ranging from $12 \mathrm{wt} \%$ to $28 \mathrm{wt} \%$. 

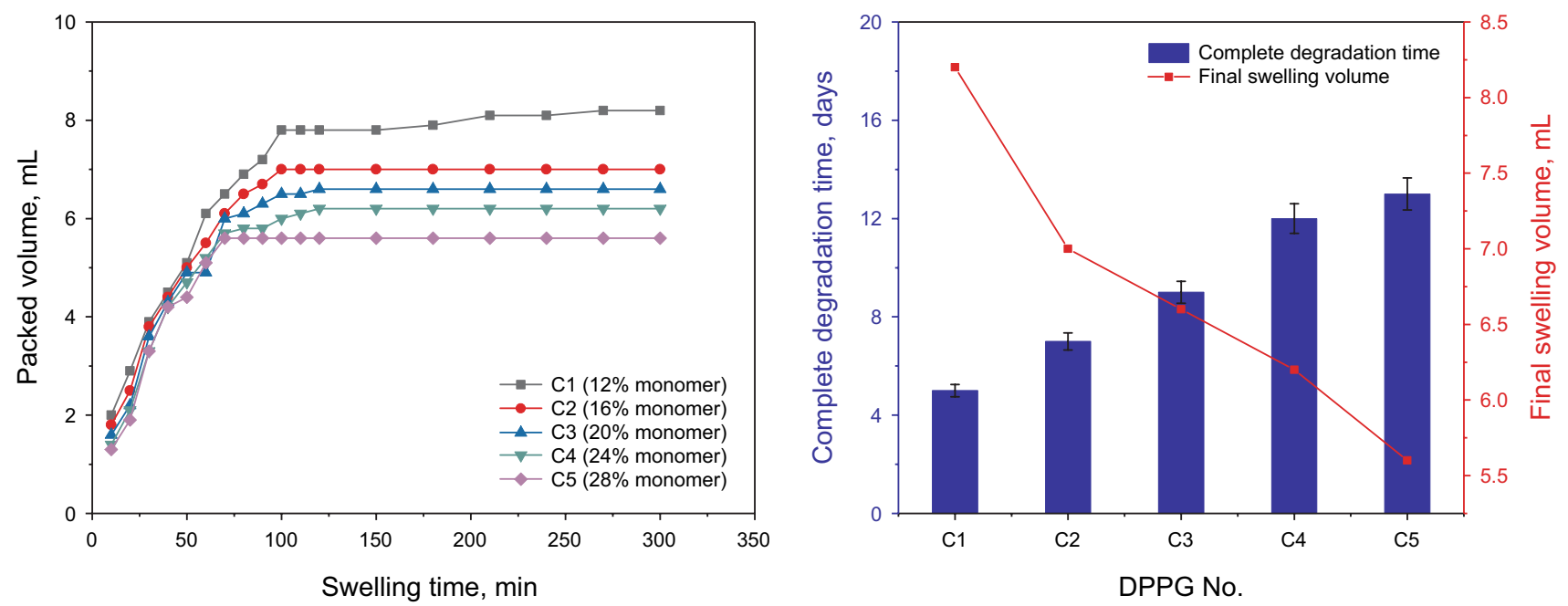

Fig. 6 Swelling and degradation performance of DPPG samples with different monomer concentrations

It can be seen from Fig. 6 that in the swelling process of the first $60 \mathrm{~min}$, all the swelling rates of DPPG samples $\mathrm{C} 1$ to $\mathrm{C} 5$ were rapid. Moreover, the swelling rate of DPPG $\mathrm{C} 1$ was the quickest, but the differences between them were small. When they were aged at $65{ }^{\circ} \mathrm{C}$ for $70 \mathrm{~min}$, the swelling volume of DPPG C5 reached the highest. The DPPG C1 reached its highest packed volume at the time of $90 \mathrm{~min}$, which shows the most excellent swelling performance. In addition, when they got their highest volumes, their swelling rates began to slow down and could almost remain stable. The final swelling volumes of DPPG samples were recorded.

In summary, the swelling performance of the DPPG samples decreased with the increase in the total monomer. The possible reason is that the more considerable the total amount of monomers in the DPPG samples, the longer the main chain of the polymer formed, and the more significant the space hindrance after cross-linking. Therefore, water molecules are more difficult to enter the inside of the polymer structure, which leads to the swelling ratio of the DPPG decreasing. Thus, in the actual oilfield operation and application process, we can adjust the total amount of monomers during the synthesis of DPPG, so that the swelling volume can be changed to adapt to the field application of different petroleum reservoir conditions. For example, according to the bridging principle of particle plugging, large particles will be suitable for large porous media in petroleum reservoirs.

After the DPPG was fully swelled in $1 \mathrm{wt} \% \mathrm{NaCl}$ solution for five hours, the free water in the test tube was taken away by a rubber-tip dropper. Then the DPPG samples were placed in an oven at $65{ }^{\circ} \mathrm{C}$ again, and the packed heights were recorded every day. The experimental results are shown in Fig. 6. The complete degradation time of DPPG $\mathrm{C} 1$ was the shortest, and the time was five days. The complete degradation time of the DPPG increased as the total amount of monomer increased. The possible reason is that the cross-linking density increases with the increase in the total amount of monomers, which can be manifested by the changes of their swelling ratio. Thus a stable threedimensional network structure is formed, resulting in an increase in the degradation time of the DPPG.

Figure 7 shows the state of the DPPG C4 when it is completely degraded. For clear observation, it can show the actual pictures before and after PPG degradation. Fifty grams of swollen DPPG samples were taken for the experiment. Before degradation, as shown in Fig. 7a, b, it was transparent water-absorbing swollen particles. After degradation, as shown in Fig. 7c, it degraded into a pale-yellow aqueous solution with a very low viscosity like water.

\subsection{Effect of cross-linker concentration on the static swelling and degradation performance of DPPG}

To study the influence of cross-linking agent concentration on the swelling volume and the complete degradation time of the temporary plugging agent, DPPG samples C6 to C10 with various cross-linker concentrations were prepared. Bottle tests were performed, and experimental results are shown in Fig. 8. In these tests, $1 \mathrm{wt} \% \mathrm{NaCl}$ aqueous solution was used.

It can be seen from Fig. 8 that in the swelling process of the first $60 \mathrm{~min}$, the overall swelling rates of the DPPG samples $\mathrm{C} 6$ to $\mathrm{C} 10$ were rapid. Moreover, the packed volume of the swelled DPPG C10 was the smallest, and the maximum swelling arrived at $60 \mathrm{~min}$. In contrast, the swelling rate of the DPPG C6 was the highest, and the maximum swelling arrived at $100 \mathrm{~min}$, which was longer than the DPPG C10. Besides, the swelling performance of the DPPG samples 


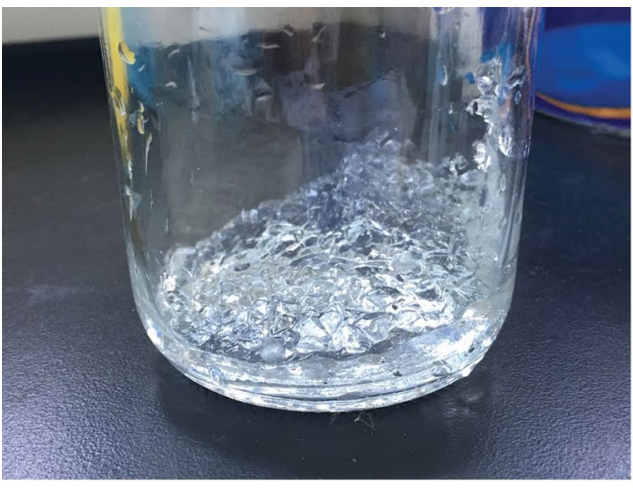

(a) Swollen DPPG before degradation

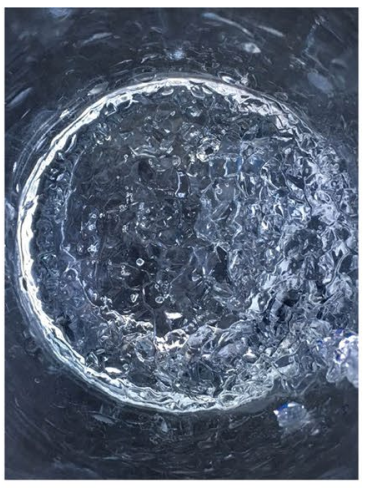

(b) Swollen DPPG in the bottle

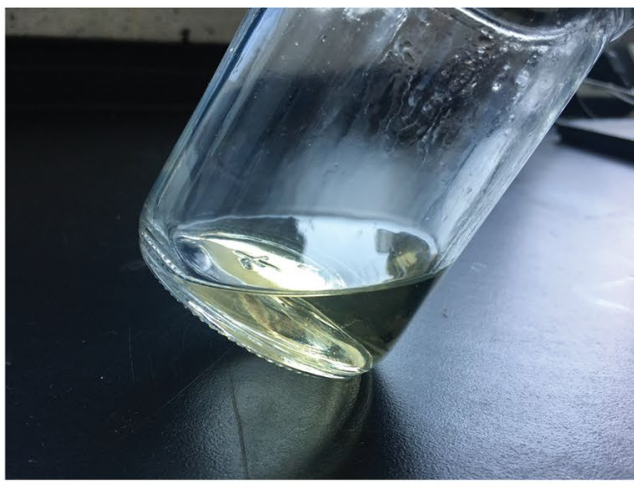

(c) After degradation

Fig. 7 DPPG C4 before and after degradation
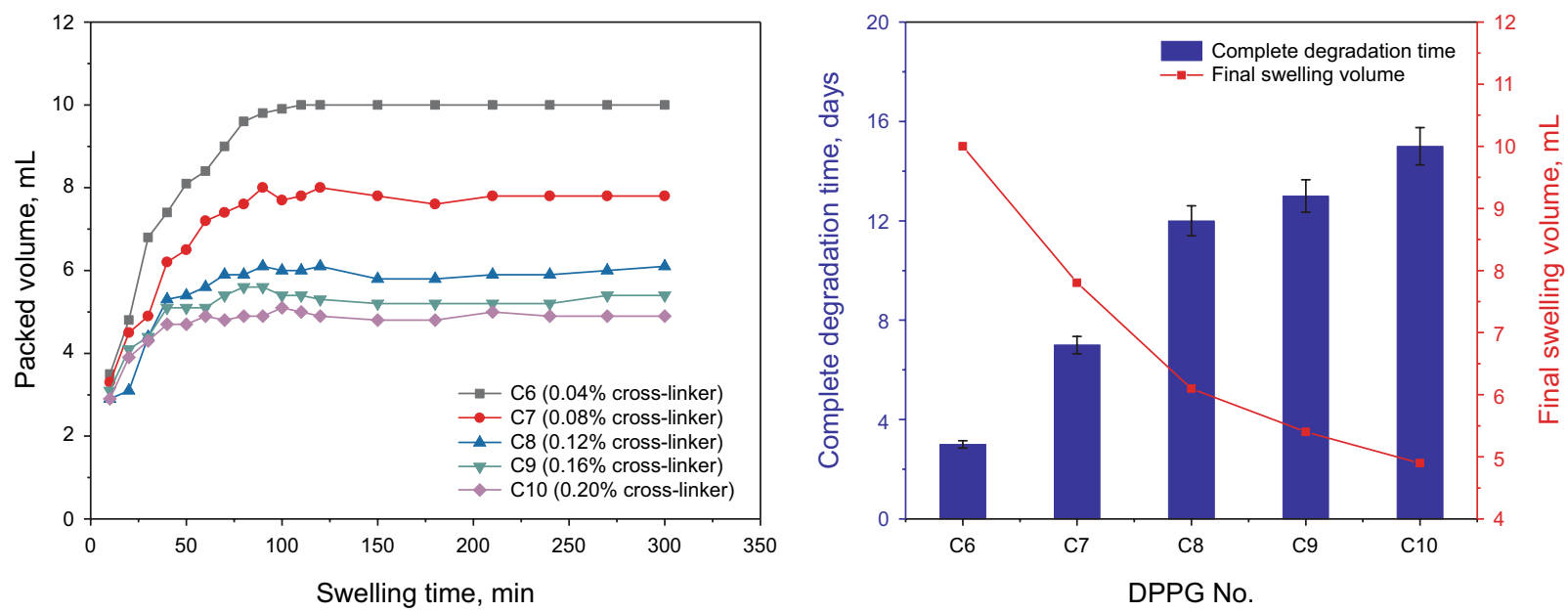

Fig. 8 Swelling and degradation performance of DPPG samples with different cross-linker concentrations

decreased with the increase in the cross-linker concentration. With the rise in the cross-linker concentration, the density of the polymer microstructure will be increased. Therefore, it is more difficult for the water molecules to enter the internal structure of the polymer, resulting in a decrease in the water absorption capacity of the DPPG. Figure 9 shows the bulk volume of the swollen DPPG samples C6 to C10 after they completely absorbed water and the free water was removed. Figure 8 also shows the degradation performance of the swollen DPPG samples (without free water) with different cross-linker concentrations over time. The cross-linker concentration of the DPPG C6 was the lowest. However, the degradation time was the fastest. Also, the degradation was completed in two days. In contrast, the complete degradation time of the DPPG C10 was the longest, and its degradation could be completed in 15 days. In summary, under the same monomer concentrations, the complete degradation time of the DPPG samples increased with an increase in the concentration of the cross-linker. The above phenomenon can also be explained in conjunction with the change rule of the swelling performance of the DPPG samples. The smaller the expansion ratio of DPPG, the denser the microscopic grid density. That is, the stronger the cross-linking density, and therefore the more time it takes to degrade.

\subsection{Effect of initiator concentration on the static swelling and degradation performance of DPPG}

To study the influence of initiator concentration on the swelling performance and complete degradation time of DPPG, different initiator concentrations (i.e., 0.4, 0.8, 1.2, 1.6, and $2.0 \mathrm{wt} \%$ ) were used to prepare DPPG samples. They were numbered as DPPG samples C11 to C15. Their compositions are shown in Table 2. The DPPG samples were dispersed in $20 \mathrm{~mL}$ of $1 \% \mathrm{NaCl}$ solution at $65^{\circ} \mathrm{C}$, and their swelling volumes over time were recorded. The results are shown in Fig. 10. 


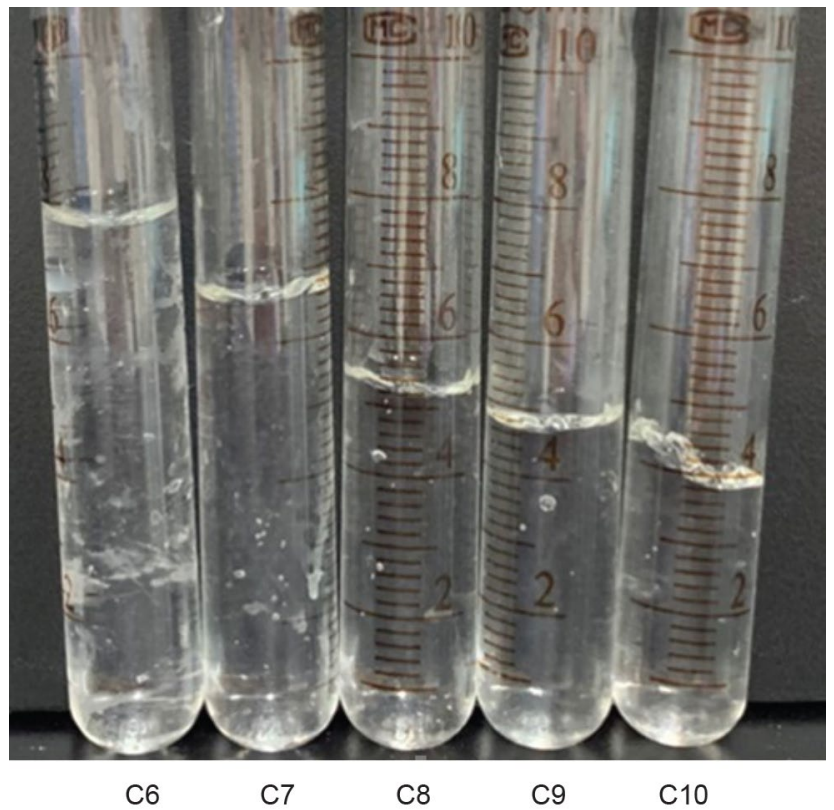

Fig. 9 Pictures of swollen DPPG samples C6 to C10 (from left to right) after they were swollen in $1 \mathrm{wt} \% \mathrm{NaCl}$ solution for $5 \mathrm{~h}$ (without free water)

It can be seen from Fig. 10 that the swelling rates of DPPG samples were very fast in the first $80 \mathrm{~min}$ of swelling with water. The swelling ratio quickly approached $60-70$ times its initial volume. However, the difference between them was relatively small. When they absorbed water for $100 \mathrm{~min}$, these five groups of DPPG samples nearly completed swelling. Among them, DPPG C14 had the most substantial swelling volume, followed by DPPG samples $\mathrm{C} 15$ and $\mathrm{C} 13$, and DPPG C11 had the lowest swelling volume. With the increase in the initiator concentration in the process of DPPG synthesis, the volume swelled with water first increased and then decreased. It is because when the initiator concentration is low, the reaction speed will increase as the initiator concentration increases, and the microscopic cross-linking density of the synthesized DPPG is low. Therefore, when the DPPG swells with water, the higher the crosslinking density of DPPG, the larger the hydration swelling volume. When the concentration of the cross-linking agent exceeds a critical concentration (e.g., $1.6 \mathrm{wt} \%$ in this study), the polymerization will rapidly exothermic, causing the local polymerization to occur quickly. This, in turn, leads to an increase in the cross-linking density of some parts of the DPPG. Therefore, the volume of its swelling with water reduces.

After the DPPG was swelled in a $1 \mathrm{wt} \% \mathrm{NaCl}$ aqueous solution for five hours, the free water around the DPPG samples in the test tube was taken away with a glue-tip dropper, and the self-degradation performance of the DPPG was evaluated. The experimental results are shown in Fig. 10. The complete degradation time of the DPPG C11 was the longest, and total degradation occurred only after 16 days of aging. The complete degradation time of the DPPG C14 was the shortest, and the complete degradation occurred on the 10th day. So, the complete degradation time of the DPPG first decreased and then increased as the initiator concentration increased, which is opposite to their swelling performance. That is, the more the expansion multiple of DPPG, the shorter the time for its complete self-degradation. It is very likely to be related to its microstructure, which will be discussed in detail in the following sections.
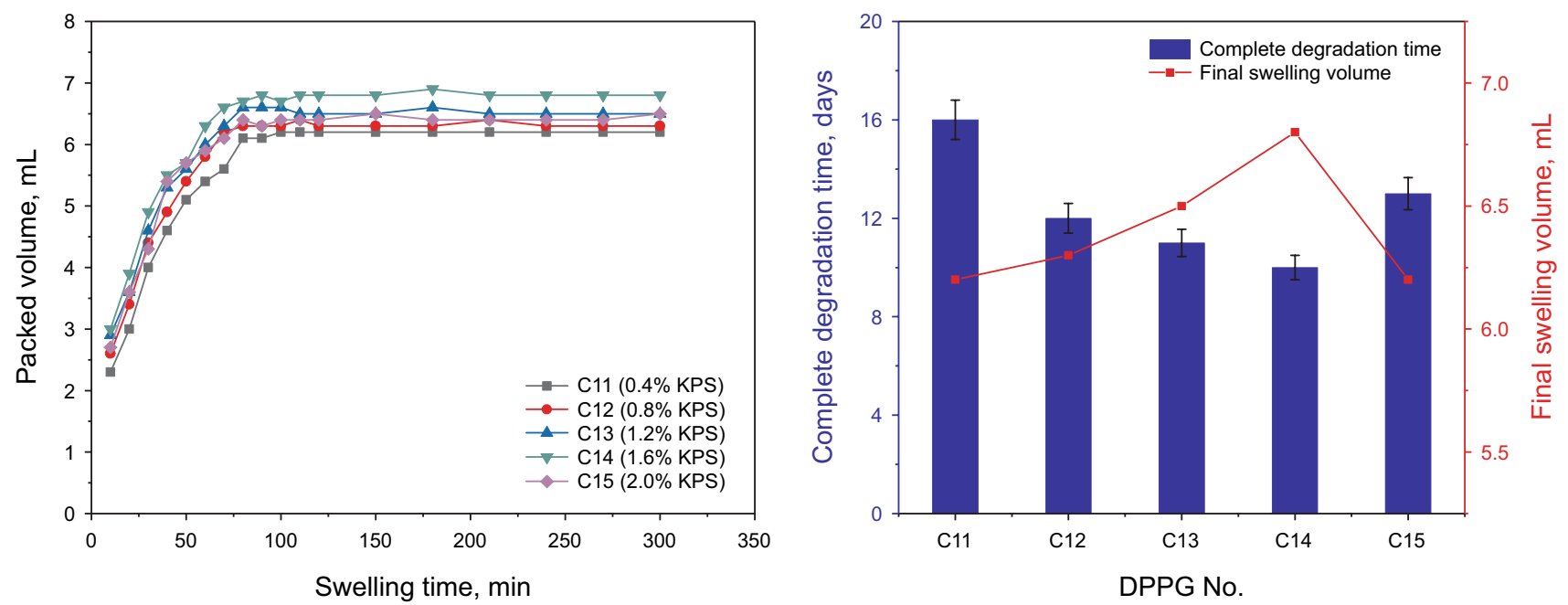

Fig. 10 Swelling and degradation performance of DPPG samples with different initiator (KPS) concentrations 


\subsection{Effect of monomer ratio on the static swelling and degradation performance of DPPG}

To study the effect of the ratio of AM to AMPS monomers in the DPPG system on the swelling and self-degradability of DPPG, DPPG samples were prepared with five different monomer ratios. Their total monomer concentration was fixed at $24 \mathrm{wt} \%$, but the ratios of AM to AMPS monomers were $3: 7,4: 6,5: 5,6: 4$, and 7:3, respectively. Their numbers are DPPG samples $\mathrm{C} 16$ to $\mathrm{C} 20$, and the specific compositions are shown in Table 2. They were dispersed in $1 \mathrm{wt} \%$ $\mathrm{NaCl}$ solution, and their swelling volumes were evaluated over time at $65^{\circ} \mathrm{C}$, and the complete degradation times were also recorded. The experimental results are shown in Fig. 11.

It can be seen from Fig. 11 that the swelling rates of DPPG samples C16 to C20 increased rapidly within $50 \mathrm{~min}$ and slowed down significantly between 50 and $100 \mathrm{~min}$. At $120 \mathrm{~min}$, the swelling of the five groups of DPPG samples was completed and remained stable. Among them, the DPPG C16 had the most substantial swelling volume, and the DPPG C20 was the smallest. So, for the DPPG samples synthesized with different monomer ratios, that is, as the concentration of AM increases or AMPS decreases in the composition, swelling volume of DPPG in $1 \mathrm{wt} \% \mathrm{NaCl}$ solution will be significantly reduced. It is mainly because AMPS is negatively charged; the repulsion between the molecular chains during synthesis will dramatically increase when the AM in the composition of DPPG decreases or AMPS increases. In addition, because the spatial volume of AMPS is much larger than that of AM, the steric hindrance effect is obvious (Zhu et al. 2017b, 2019). Therefore, it can play the role of expanding the grid, making the grid density smaller during cross-linking (i.e., the grid size becomes more substantial). In addition, as the proportion of AMPS in the DPPG system increases, the final expansion volume when it encounters water will also be more significant.

When the above five kinds of DPPG samples swelled in water for five hours, the free water around them was taken away, and the swollen particles were retained for self-degradation experiments. The results show that the complete selfdegradation time of the DPPG C16 was the shortest, which was two days. The self-degradation time of the DPPG C20 was the longest (12 days). Moreover, there was an obvious opposite relationship between the complete self-degradation time and the final swelling volume. That is, as the swelling volume of the DPPG increased, its complete degradation time would decrease.

\subsection{Effect of reservoir brine salinity and temperature on the static swelling and degradation performance of DPPG}

To study the influence of reservoir brine salinity and temperature on the swelling effect of DPPG, we selected $0.1 \mathrm{~g}$ of the DPPG C14 with a particle size of 20-30 mesh as an example. The salinity was $1 \%, 2 \%, 5 \%, 10 \%, 15 \%$, and $20 \%$, separately, and the temperature ranged from 45 to $150{ }^{\circ} \mathrm{C}$. The packed volume and complete degradation time of these DPPG samples were recorded, as shown in Fig. 12. It shows the swelling and degradation performance of DPPG samples at different reservoir brine salinity and temperatures.

As the brine salinity increased from $1 \mathrm{wt} \%$ to $20 \mathrm{wt} \%$, the final swelling volume of DPPG samples decreased. The main reason is that with an increase in the degree of brine salinity, salt ions can enhance the shielding capacity of the counterions on sulfonic acid and carboxyl anions. Therefore, the hydration capacity of the hydrophilic functional groups of the polymer chains in the DPPG increases,
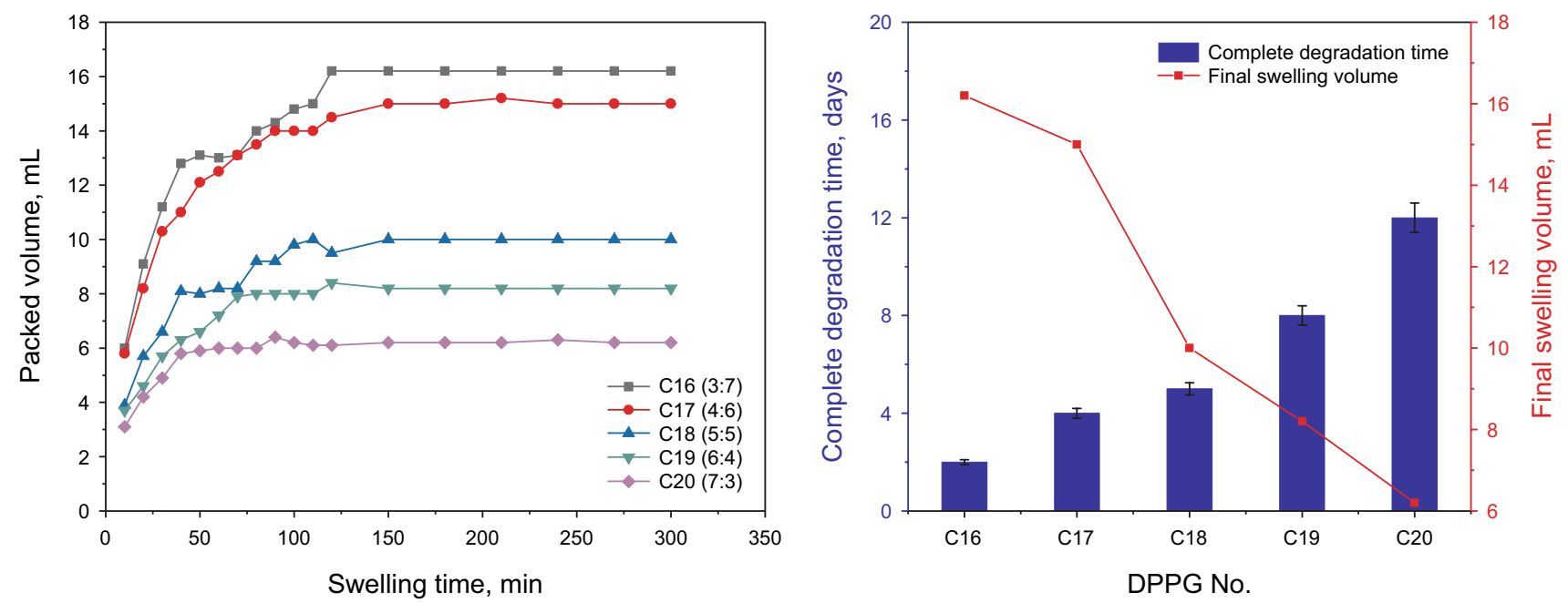

Fig. 11 Swelling and degradation performance of DPPG samples with different monomer ratios of AM to AMPS 

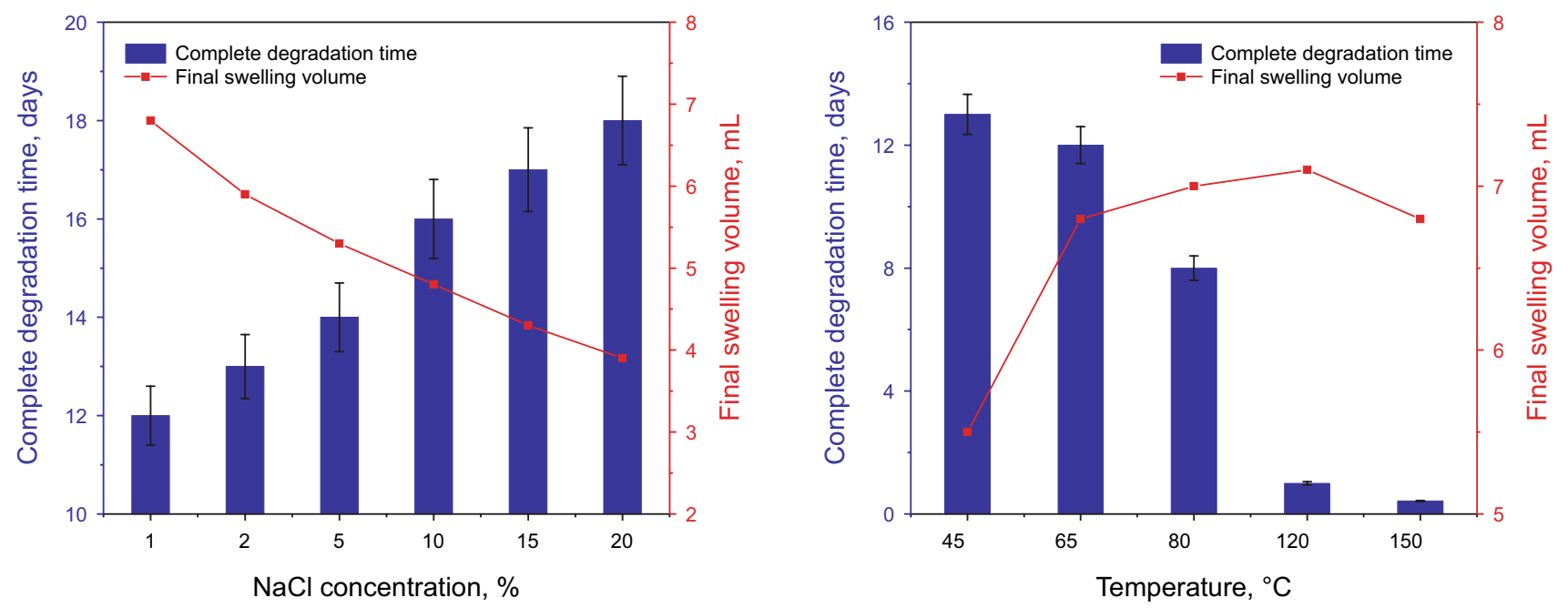

Fig. 12 Swelling and degradation performance of DPPG samples at different brine salinity and temperatures

and then the reverse polyelectrolyte effect can lead to the shrinkage and curling of the polymer chains. Therefore, the water absorption capacity of the polymer reduces. In addition, the degradation rate of the DPPG previously swollen by the salinity of $1 \mathrm{wt} \% \mathrm{NaCl}$ was the fastest, and the degradation was completed on the tenth day. However, the degradation rate of the DPPG previously swollen by the salinity of $20 \mathrm{wt} \% \mathrm{NaCl}$ was the slowest, and the degradation was completed on the 18 th day. Therefore, the DPPG shows excellent salt tolerance, even in the solution of $20 \%$ salinity. The swelling performance is still satisfactory and can be completely degraded into water-like solutions. Moreover, there is also an apparent opposite relationship between the final swelling volume and the complete self-degradation time. That is, with an increase in the swelling volume of DPPG, its complete degradation time will decrease.

As for the influence of reservoir temperature, when the DPPG C14 swelled in brine at $45^{\circ} \mathrm{C}$, its final swelling volume was $5.5 \mathrm{~mL}$, this swelling capacity is still suitable for oilfield operations. With the increase in the aging temperature from 60 to $120^{\circ} \mathrm{C}$, the final swelling volume increased slightly. However, it is worth noting that when DPPG was aged at $150{ }^{\circ} \mathrm{C}$ for $210 \mathrm{~min}$ in the saline solution, its packed volume decreased. It is mainly because under extremely high-temperature conditions, the temperature resistance of the functional groups AM and AMPS is limited, leading to high-temperature hydrolysis in part of the polymer chains of DPPG. This allows part of the DPPG to be dissolved in the aqueous solution, so the packed volume reduces accordingly. In summary, as the temperature increases, the swelling ratio of the DPPG also increases. Therefore, this series of DPPG shows excellent high-temperature adaptability, which can be applied to reservoirs even with the temperatures up to
$150{ }^{\circ} \mathrm{C}$. After the DPPG C14 was fully expanded for $5 \mathrm{~h}$, the DPPG being aged at $150{ }^{\circ} \mathrm{C}$ had the fastest degradation time. The degradation was completed at $12 \mathrm{~h}$. However, the DPPG being aged at $45^{\circ} \mathrm{C}$ had the lowest degradation rate, and the complete degradation was achieved after 13 days. In summary, the higher the temperature, the faster the degradation rate of the DPPG. It is mainly because as the experimental temperature increases, the hydrolysis rate of the amide group and the self-breaking of $\mathrm{C}-\mathrm{O}$ bond of the polymeric cross-linker (DT-2) increases, and thus the degradation rate increases.

\subsection{Morphology and microstructure changes of DPPG during self-degradation}

To study the changes in the morphology and microstructure of the DPPG during the self-degradation process, we arbitrarily selected the DPPG C14 as the research object for observation. First, we weighed $0.1 \mathrm{~g}$ of DPPG C14 with a dry particle size of 20-30 mesh, dispersed it in $20 \mathrm{~mL}$ of $1 \%$ $\mathrm{NaCl}$ solution, and then placed it in a thermostat at $65^{\circ} \mathrm{C}$ for aging. After swelling for five hours, the free water was taken away, and the swollen DPPG was retained. Then the morphology changes of the DPPG under different aging times at $65^{\circ} \mathrm{C}$ were investigated using an optical microscope. When the DPPG was degraded entirely, we took a small amount of the dissolved liquid and used a Brookfield viscometer to measure the viscosity of the degraded solution.

Figure 13 shows that when the DPPG was fully expanded for $5 \mathrm{~h}$, the shape of the particles was a solid gel particle with sharp edges and corners. It had a certain degree of elasticity and viscosity. After being placed in the oven for $24 \mathrm{~h}$, the edge of the temporary plugging agent began to soften. However, the overall change was not noticeable. When it 


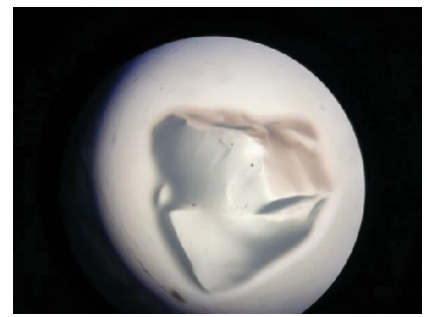

(a) Aged for $5 \mathrm{~h}$

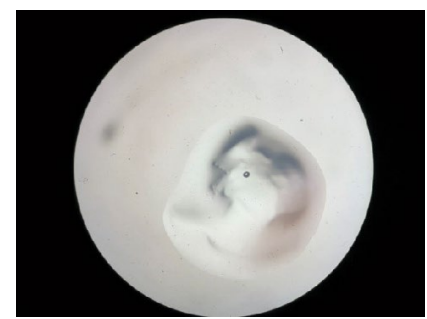

(e) Aged for $96 \mathrm{~h}$

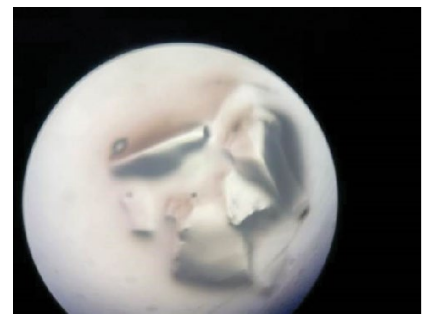

(b) Aged for $24 \mathrm{~h}$

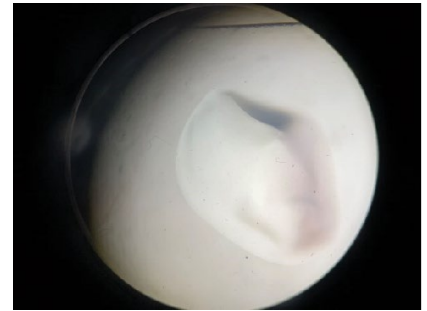

(f) Aged for $120 \mathrm{~h}$

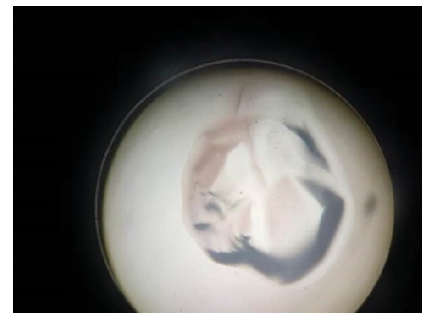

(c) Aged for $48 \mathrm{~h}$

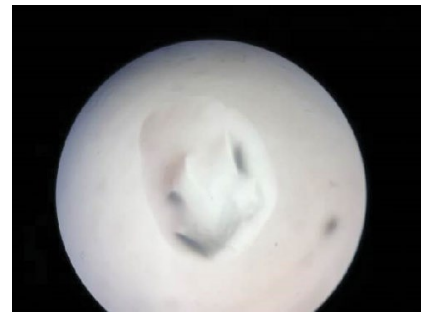

(g) Aged for $144 \mathrm{~h}$

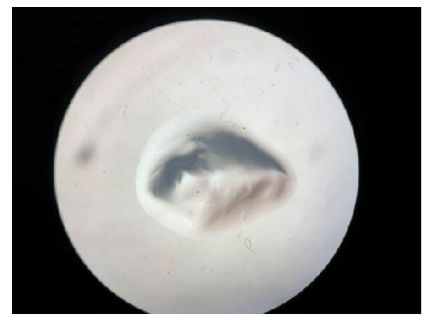

(d) Aged for $72 \mathrm{~h}$

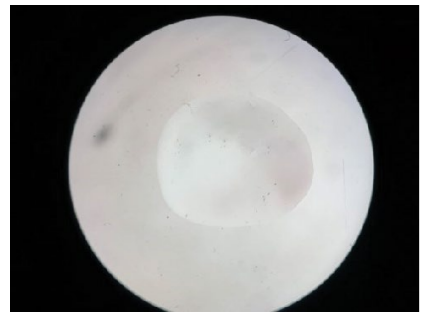

(h) Aged for $192 \mathrm{~h}$

Fig. 13 Morphology changes of DPPG samples during the self-degradation process

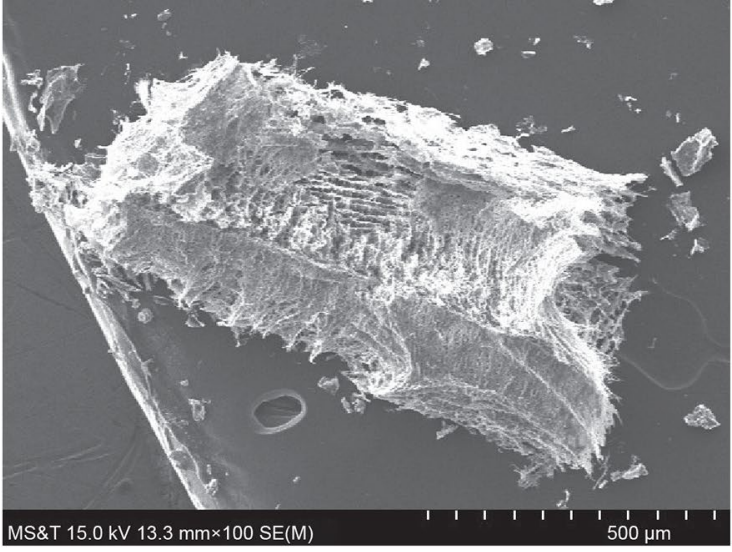

(a) Swollen DPPG $(\times 100)$

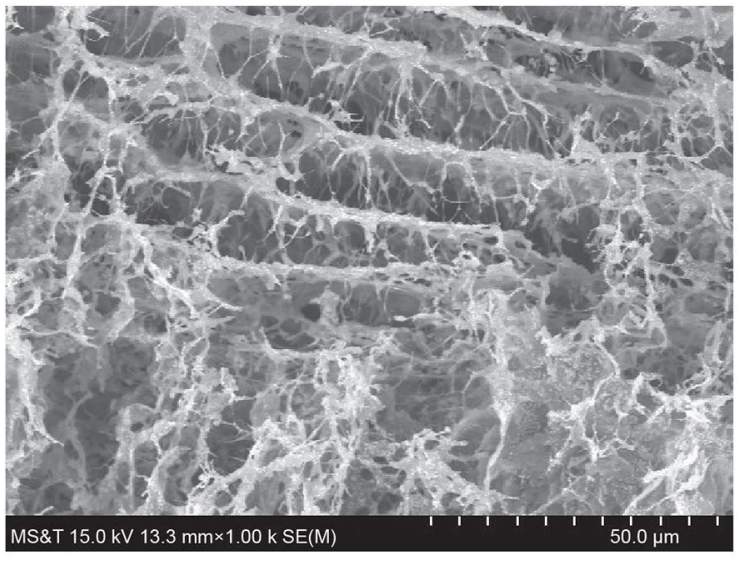

(c) Swollen DPPG $(\times 1000)$

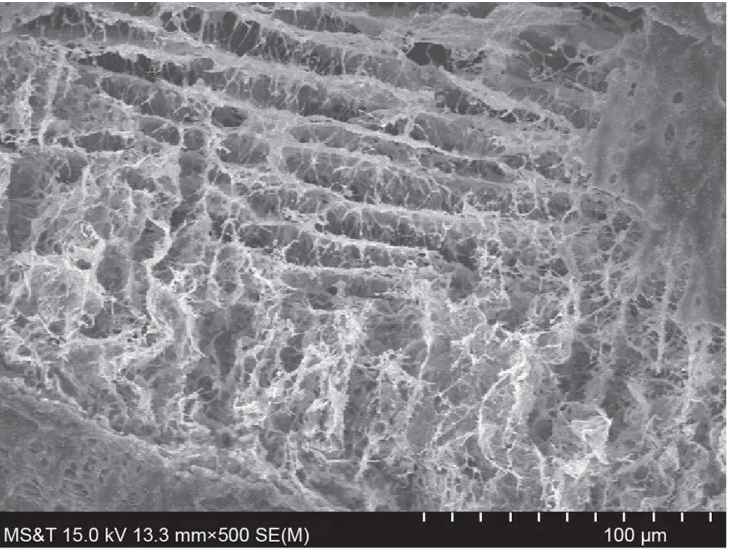

(b) Swollen DPPG $(\times 500)$

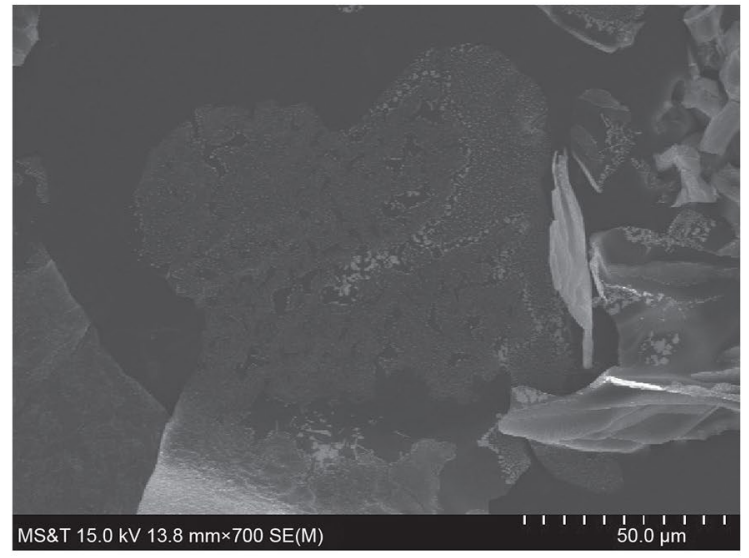

(d) Degraded DPPG $(\times 700)$

Fig. 14 Microstructure changes of DPPG samples during the self-degradation process 
was aged for $48 \mathrm{~h}$, the edges and corners of the swollen particles became smooth, and some edges and corners began to degrade. After $72 \mathrm{~h}$, the peripheral edges and corners of the swollen particles were all degraded and became very smooth. At the aging time of $96 \mathrm{~h}$, the edges of the swollen particles began to degrade and shrink inwardly. After $192 \mathrm{~h}$, the DPPG particles had been completely degraded to be a liquid flow state. Then, the Brookfield viscometer was used to measure the viscosity of the degraded liquid, which was $2.6 \mathrm{mPa}$ s. Therefore, the viscosity of the degraded DPPG is lower, which has little damage to the formation.

Figure 14 shows the scanning electron microscope (SEM) images of swollen DPPG C14 before and after self-degradation. It can be seen from Figs. $14 \mathrm{a}-\mathrm{c}$ that the monomers AM and AMPS can form a dense spatial three-dimensional microscopic network by adding the self-degradable monomer DT-2 (its primary function is cross-linking). These hydrophilic networks can expand rapidly after encountering water molecules, as shown in Fig. 13. And, the smaller the grid density of gel microstructure (i.e., the larger the pores between the grids), the more water molecules can enter. Therefore, the swelling ratio of the corresponding DPPG is also higher. This, in turn, explains the previous experimental results. That is, as the monomer concentration or the crosslinking agent concentration decreases, the grid density of the formed DPPG is smaller, and the expansion ratio is higher. In addition, with an increase in the proportion of AMPS in the system, the steric hindrance effect is strengthened, the grid density of the synthesized DPPG is significantly reduced, thus the swelling ratio will be increased considerably. In addition, the smaller the grid density of the gel, the larger the pore size in the grid, the more conducive to the self-degradation of swollen DPPGs. Figure 14d shows the SEM image of DPPG C14 after degradation. There is no visible particle and network structure, and almost all DPPG has been degraded. It is due to the introduction of the degradable DT-2 functional structure into the DPPG structure. It can undergo self-degradation and finally degrade into a solution with a viscosity close to water. Therefore, the damage of the DPPG to the formation is minimal.

\subsection{Core displacement experiment}

The previous parts have studied the static expansion and self-degradability of DPPG. To further verify that DPPG particles have sound temporary plugging effects under real reservoir conditions, we also used artificial cores for displacement experiments. The drilled cylindrical core use is shown in Fig. 2. The purpose of the drilling is to simulate the high-permeability layer in the petroleum reservoir so that a certain volume of DPPG can be injected into the core, and thus form a certain plugging. The experimental results of the core displacement experiment are shown in Fig. 15.

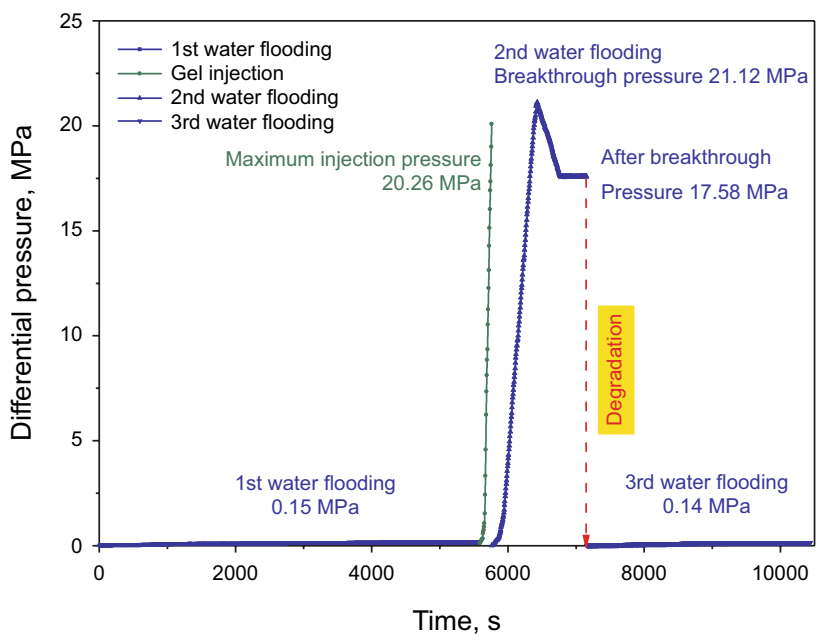

Fig. 15 Core displacement curve of DPPG C14

In the stage of the DPPG injection, the swollen particles were injected at a flow rate of $2 \mathrm{~mL} / \mathrm{min}$. The pressure gradient between the two ends of the core can be seen to rise rapidly. When the injection pressure of DPPG reached $20 \mathrm{MPa}$, water was injected. The water injection pressure can be as high as $21.12 \mathrm{MPa}$. This indicates that the DPPG has excellent plugging performance. As the injection of water continues, the water flow will form a flow channel along the surface of the compacted deformed particles under the injection pressure gradient. However, compared to the previously drilled channel, water mobility is significantly decreased. So, the breakthrough pressure gradient of DPPG can be $17.58 \mathrm{MPa}$, which means the DPPG can significantly decrease the core permeability to water. Then, the plugged core was sealed and aged in an oven at $65{ }^{\circ} \mathrm{C}$. After the DPPG was degraded entirely, the water flooding test was performed on the core again. It can be seen from Fig. 15 that the core permeability after degradation of the temporary plugging agent is measured to be $24.26 \times 10^{-3} \mu \mathrm{m}^{2}$, which is a little higher than its original permeability $\left(26.65 \times 10^{-3} \mu \mathrm{m}^{2}\right)$. Therefore, DPPG has little damage to the low-permeability layer of the core. So, it can be seen from core displacement experiments that DPPG has excellent plugging performance in reservoir cores. Besides, it can become a solution with a viscosity like water through self-degradation. Thus, it has very little damage to the core permeability. Therefore, DPPG has an excellent temporary plugging effect and can be used as a temporary plugging material with high application potential.

\subsection{Discussion on the synthesis, expansion and self-degradation mechanism of DPPG}

In the previous section, we have discussed in detail the results of the bottle test method and core displacement 


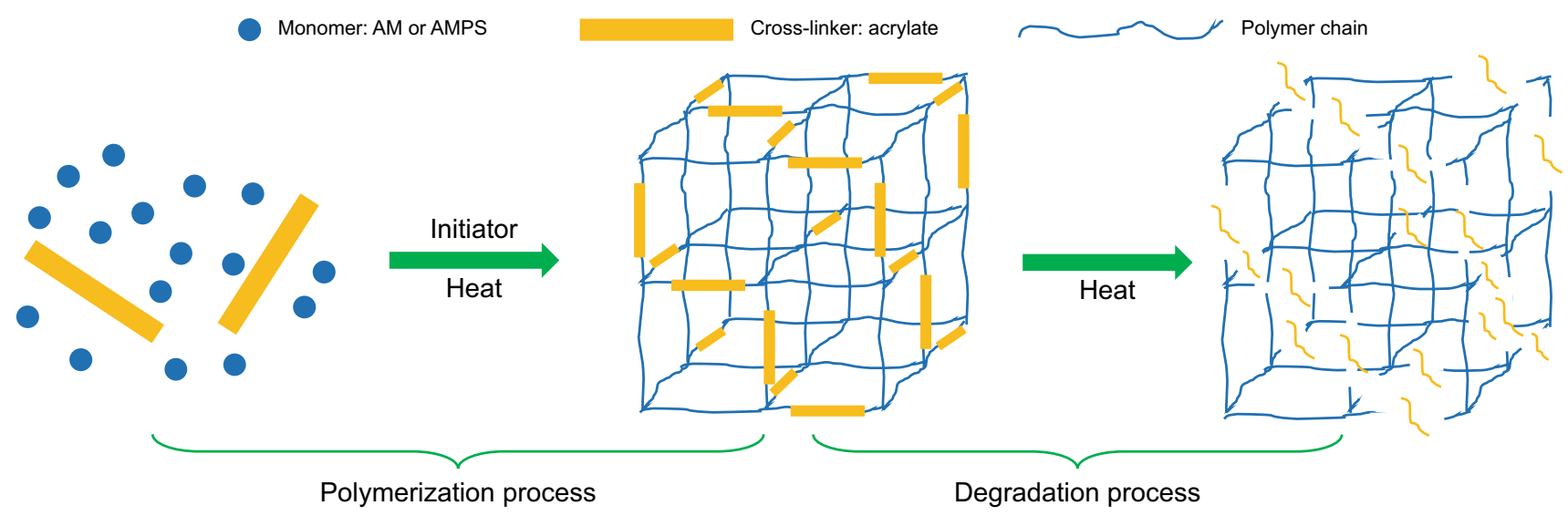

Fig. 16 Synthesis, expansion and self-degradation mechanism of DPPG

experiment of DPPG, as well as its microscopic morphology characteristics and changes. Based on these, we can propose the following synthesis and self-degradation mechanisms of DPPG, as shown in Fig. 16, which will further facilitate the understanding of the above experimental results. First, the low molecular weight monomers of acrylamide (AM) and 2-acrylamide-2-methylpropanesulfonic acid (AMPS) can undergo a polymerization under the cross-linking effect of the low molecular weight polymer DT-2 through free radical polymerization. Thus, a microscopic three-dimensional network of polymer molecules DPPG can be formed. Since each monomer in the polymer (i.e., AM and AMPS) has excellent hydrophilicity, when the DPPG encounters water, it can quickly swell. That is, water molecules can enter the DPPG microscopic grid through osmotic hydration. And, the smaller the grid density, the larger the pores between the grids, and therefore more water molecules can be absorbed. That is, it has a more water-absorbing swelling ratio. Besides, the more AMPS monomer content in the system, the more obvious the steric hindrance effect of AMPS is. Therefore, the larger the size of the spatial microgrid formed, the more water can be absorbed, and the better the expansion effect in saltwater. Furthermore, in the self-degradation stage of DPPG, due to the spreading effect of DT-2, the structure can be broken by itself. Therefore, the grid of the entire three-dimensional network is gradually disassembled. Finally, it is completely degraded into an aqueous solution of ultra-low molecular weight residues. Therefore, DPPG, as a temporary plugging agent (TPA), has very little damage to the formation.

\section{Conclusions}

A degradable pre-formed particle gel (DPPG) was developed and used as the temporary plugging agent (TPA) for petroleum reservoir drilling and production. Bottle tests were used to evaluate the influence of the composition of the DPPG on the static temporary plugging performance. Then the reservoir adaptability of the optimized DPPG was evaluated. Finally, the core displacement experiment was used to investigate the plugging and degradation performance of DPPG in the porous medium. The main conclusions are as follows:

(1) The decrease in the total number of monomers and cross-linker or the increase in the concentration of monomer AMPS will cause an increase in DPPG swelling volume and a decrease in the complete degradation time.

(2) As the content of the initiator increases, the final swelling volume of the DPPG first increases and then decreases. However, the change in the complete degradation time is just the opposite.

(3) The DPPG has excellent temperature resistance and salinity resistance. The temperature resistance was up to $150{ }^{\circ} \mathrm{C}$, and the salinity resistance could reach $200,000 \mathrm{mg} / \mathrm{L}$.

(4) For the sandstone core with a partially opened fracture and an initial permeability of $26.65 \times 10^{-3} \mu \mathrm{m}^{2}$, the pressure gradient of DPPG plugging between the two ends of the core could reach $21.12 \mathrm{MPa}$. And the permeability could be restored to $24.26 \times 10^{-3} \mu \mathrm{m}^{2}$ after temporary plugging. That is, the core permeability recovery rate was about $91 \%$. Therefore, DPPG has high plugging strength and low core damage.

(5) DPPG has a relatively regular spatial three-dimensional microscopic network, which makes it have an excellent water swelling effect. The smaller the grid 
density, the larger the pores between the grids, the stronger the water absorption capacity, and the shorter the time required for complete self-degradation.

\begin{abstract}
Acknowledgements This work was supported by the Research Foundation of China University of Petroleum-Beijing at Karamay (No. XQZX20200010), the Natural Science Foundation of Xinjiang Uygur Autonomous Region (No. 2019D01B57), the University Scientific Research Project of Xinjiang Uygur Autonomous Region (No. XJEDU2019Y067), the Xinjiang Uygur Autonomous Region Innovation Environment Construction Project (No. 2019Q025), the Sichuan Province Regional Innovation Cooperation Project (No. 2020YFQ0036), and the CNPC Strategic Cooperation Science and Technology Project (ZLZX2020-01-04-04).
\end{abstract}

Open Access This article is licensed under a Creative Commons Attribution 4.0 International License, which permits use, sharing, adaptation, distribution and reproduction in any medium or format, as long as you give appropriate credit to the original author(s) and the source, provide a link to the Creative Commons licence, and indicate if changes were made. The images or other third party material in this article are included in the article's Creative Commons licence, unless indicated otherwise in a credit line to the material. If material is not included in the article's Creative Commons licence and your intended use is not permitted by statutory regulation or exceeds the permitted use, you will need to obtain permission directly from the copyright holder. To view a copy of this licence, visit http://creativecommons.org/licenses/by/4.0/.

\section{References}

Allison D, Curry S, Todd B. Restimulation of wells using biodegradable particulates as temporary diverting agents. In: Canadian unconventional resources conference. 2011. https://doi.org/https ://doi.org/10.2118/149221-MS.

Bai B, Li L, Liu Y, Liu H, Wang Z, You C. Preformed particle gel for conformance control: factors affecting its properties and applications. SPE Reserv Eval Eng. 2007;10(04):415-22. https://doi. org/10.2118/89389-MS.

Bai B, Liu Y, Coste J, Li L. Preformed particle gel for conformance control: transport mechanism through porous media. SPE Reserv Eval Eng. 2007;10(02):176-84. https://doi.org/10.2118/89468 -PA.

Cargnel R, Luzardo J. Particle size distribution selection of $\mathrm{CaCO}_{3}$ in drill-in fluids: theory and applications. In: Latin American and Caribbean petroleum engineering conference. 1999. https://doi. org/10.2118/53937-MS.

Du Z, Li J, Nie H. A probe of secondary deflection fracturing treatment in hydraulic fractures. Xinjiang Pet Geol. 2013;34(3):349-53 ((in Chinese)).

Elsharafi M, Bai B. Influence of strong preformed particle gels on low permeable formations in mature reservoirs. Pet Sci. 2016;13(1):77-90. https://doi.org/10.1007/s12182-015-0072-3.

Huo B. The study of high-temperature oil-soluble temporary plugging agent. M.S. thesis. Daqing Petroleum Institute. 2009. https ://kns.cnki.net/kcms/detail/detail.aspx?FileName $=2009215942$ .nh $\&$ DbName $=$ CMFD2010. (in Chinese)

Jia H, Yang X, Li S, Yu P, Zhang J. Nanocomposite gel of high-strength and degradability for temporary plugging in ultralow-pressure fracture reservoirs. Colloids Surf A. 2020;585:124108. https:// doi.org/10.1016/j.colsurfa.2019.124108.
Jiang B, Mu L. Study on the performance of wax-bead temporary blocking agent used for refracturing in low-permeability reservoir. Drill Prod Technol. 2006;6(29):114-6 ((in Chinese)).

Kang Y, Xu C, You L, Yu H, Zhang D. Temporary sealing technology to control formation damage induced by drill-in fluid loss in fractured tight gas reservoir. J Nat Gas Sci Eng. 2014;20:67-73. https://doi.org/10.1016/j.jngse.2014.06.016.

Li W, Zhao H, Pu H, Zhang Y, Wang L, Zhang L, Sun X. Study on the mechanisms of refracturing technology featuring temporary plug for fracturing fluid diversion in tight sandstone reservoirs. Energy Sci Eng. 2019;7(1):88-97. https://doi.org/10.1002/ese3.259.

Li C, Yang S, Wen Z, Pan Y, Zeng F, Zhao C, Abouleilah H. The research of new type gel plugging agent for deep well. Energy Sourc Part A Recov Util Environ Eff. 2020. https://doi. org/10.1080/15567036.2020.1756538.

Liu P, Wei F, Zhang S, Zhu X. A bull-heading water control technique of thermo-sensitive temporary plugging agent. Pet Explor Dev. 2018;45(3):536-43. https://doi.org/10.1016/S1876 -3804(18)30059-4.

Liu S, Guo T, Rui Z, Ling K. Performance evaluation of degradable temporary plugging agent in laboratory experiment. J Energy Res Technol. 2020;142(12):123002. https://doi.org/10.1115/1.40473 11.

Lv B, Mu L, Zhao Z, Lu H. Low-density, high-strength degradable temporary pugging agent and the preparation method and use thereof. US Patents. 2019. https://patentimages.storage.googleapis.com/ b3/88/4a/ec08286542f652/US20190136116A1.pdf.

Nasiri A, Ghaffarkhah A, Moraveji MK, Gharbanian A, Valizadeh M. Experimental and field test analysis of different loss control materials for combating lost circulation in bentonite mud. J Nat Gas Sci Eng. 2017;44:1-8. https://doi.org/10.1016/j.jngse.2017.04.004.

Reddy B, Cortez J. Activator development for controlling degradation rates of polymeric degradable diverting agents. In: SPE international symposium on oilfield chemistry. 2013. https://doi.org/https ://doi.org/10.2118/164117-MS.

Reddy B, Cortez J, Ogle J. Wellbore servicing methods and compositions comprising degradable polymers. US Patents. 2018. https:// patentimages.storage.googleapis.com/79/18/3b/3e102b13516774/ US9410076.pdf.

Schultz R, Watson B, Ferguson A, Funkhouser G. Flow control in subterranean wells. US Patents. 2020. https://patentimages.stora ge.googleapis.com/e0/58/23/bfadbbb06ccfca/US9523267.pdf.

Shi X, Zhang W, Xu H, Xiao C, Jiang S. Experimental study of hydraulic fracture initiation and propagation in unconsolidated sand with the injection of temporary plugging agent. J Pet Sci Eng. 2020;190:106813. https://doi.org/10.1016/j.petrol.2019.106813.

Surjaatmadja J, Todd B. Fracturing fluids comprising degradable diverting agents and methods of use in subterranean formations. US Patents. 2009. https://patentimages.storage.googleapis .com/53/8f/2a/2b1239e76e52c3/US7506689.pdf.

Takahashi T, Okura M, Takahashi S, Kobayashi T, Kobayashi F, Sato H. Temporary plugging agent for well drilling. US Patents. 2016. https://patentimages.storage.googleapis.com/18/8e/6e/dba52 68184072b/US20160298017A1.pdf.

Wang B, Zhou F, Yang C, Wang D, Yang K, Liang T. Experimental study on injection pressure response and fracture geometry during temporary plugging and diverting fracturing. SPE J. 2020;25(02):573-86. https://doi.org/10.2118/199893-PA.

Wang Z, Bai B. Preformed-particle-gel placement and plugging performance in fractures with tips. SPE J. 2018;23(6):2316-26. https ://doi.org/10.2118/193997-PA.

Wang Z, Bai B, Sun X, Wang J. Effect of multiple factors on preformed particle gel placement, dehydration, and plugging performance in partially open fractures. Fuel. 2019;251:73-81. https://doi. org/10.1016/j.fuel.2019.04.027. 
Wang Z, Bai B, Zhou E, Pu J, Schuman T. Experimental evaluation of oxidizing breakers for a polyacrylamide-based re-crosslinkable preformed particle gel. Energy Fuels. 2019;33(6):5001-10. https ://doi.org/10.1021/acs.energyfuels.9b00709.

Wei B. Evaluation of preformed particle gel as a diverting agent for acidizing. M.S. thesis. Missouri University of Science and Technology. 2017. https://scholarsmine.mst.edu/masters_theses/7728.

Xiong C, Shi Y, Zhou F, Liu X, Yang X, Yang X. High efficiency reservoir stimulation based on temporary plugging and diverting for deep reservoirs. Pet Explor Dev. 2018;45(5):948-54. https://doi. org/10.1016/S1876-3804(18)30098-3.

Xue S, Zhang Z, Wu G, Wang Y, Wu J, Xu J. Application of a novel temporary blocking agent in refracturing. In: SPE Asia Pacific unconventional resources conference and exhibition. 2015. https:// doi.org/https://doi.org/10.2118/176900-MS.

Yuan L, Zhou F, Li B, Gao J, Yang X, Cheng J, Wang J. Experimental study on the effect of fracture surface morphology on plugging efficiency during temporary plugging and diverting fracturing. $\mathbf{J}$ Nat Gas Sci Eng. 2020;81:103459. https://doi.org/10.1016/j.jngse .2020.103459.

Zhang H, Zhong Y, She J, Kuang J. Experimental study of nanodrilling fluid based on nano temporary plugging technology and its application mechanism in shale drilling. Appl Nanosci. 2019;9(8):1637-48. https://doi.org/10.1007/s13204-019-01046-w.

Zhang L, Zhou F, Mou J, Pournik M, Tao S, Wang D, Wang Y. Largescale true tri-axial fracturing experimental investigation on diversion behavior of fiber using 3D printing model of rock formation. J Pet Sci Eng. 2019;181:106171. https://doi.org/10.1016/j.petro 1.2019.06.035.

Zhang L, Zhou F, Feng W, Cheng J. Temporary plugging mechanism of degradable diversion agents within reproduced acid-etched fracture by using 3D printing model. In: Abu Dhabi international petroleum exhibition and conference. 2019c. https://doi.org/https ://doi.org/10.2118/197132-MS.

Zhang L, Zhou F, Mou J, Feng W, Li Z, Zhang S. An integrated experimental method to investigate tool-less temporary-plugging multistage acid fracturing of horizontal well by using selfdegradable diverters. SPE J. 2020;25(03):1204-19. https://doi. org/10.2118/199884-PA.

Zhang L, Zhou F, Feng W, Pournik M, Li Z, Li X. Experimental study on plugging behavior of degradable fibers and particulates within acid-etched fracture. J Pet Sci Eng. 2020;185:106455. https://doi. org/10.1016/j.petrol.2019.106455.

Zhao G, Dai C, Li W, Yan Z, Zhao M. Research on a temporary plugging agent based on polymer gel for reservoir acidification. J Pet Explor Prod Technol. 2016;6(3):465-72. https://doi.org/10.1007/ s13202-015-0206-6.

Zhao L, Chen X, Zou H, Liu P, Liang C, Zhang N, Li N, Luo Z, Du J. A review of diverting agents for reservoir stimulation. J Pet Sci Eng. 2020;187:106734. https://doi.org/10.1016/j.petrol.2019.106734.

Zhou J. Strength adjustable preformed particle gels for conformance control. Ph.D. dissertation. Missouri University of Science and Technology, Rolla. 2011. https://scholarsmine.mst.edu/docto ral_dissertations/2368.

Zhu D, Bai B, Hou J. Polymer gel systems for water management in high-temperature petroleum reservoirs: a chemical review. Energy Fuels. 2017;31(12):13063-87. https://doi.org/10.1021/acs.energ yfuels.7b02897.

Zhu D, Hou J, Wei Q, Wu X, Bai B. Terpolymer gel system formed by resorcinol-hexamethylenetetramine for water management in extremely high-temperature reservoirs. Energy Fuels. 2017;31(2):1519-28. https://doi.org/10.1021/acs.energyfuel s.6b03188.

Zhu D, Hou J, Chen Y, Wei Q, Zhao S, Bai B. Evaluation of terpolymer-gel systems crosslinked by polyethylenimine for conformance improvement in high-temperature reservoirs. SPE J. 2019;24(04):1-726. https://doi.org/10.2118/194004-PA.

Zou Y, Ma X, Zhang S. Numerical modeling of fracture propagation during temporary-plugging fracturing. SPE J. 2019;25(03):150322. https://doi.org/10.2118/199351-PA. 